\title{
Publishing tRends fOR the CyCADALes, the MOST threatened PLANT GROUP
}

\section{April N. Cascasan ${ }^{1}$ \& Thomas E. Marler ${ }^{2}$}

SSN 0974-7907 (Online) ISSN 0974-7893 (Print)

1,2 Western Pacific Tropical Research Center, University of Guam Mangilao, Guam 96923 USA

${ }^{1}$ Current address: Department of Botany, University of Hawaii at Manoa, 3190 Maile Way, Honolulu, Hawaii 96816 USA

12anjc@hawaii.edu, ${ }^{2}$ thomas.marler@gmail.com (corresponding author)

Abstract: Trends in published cycad research within various fields of study were determined using proceedings from international conferences on cycad biology and Google Scholar to access the primary literature. Both search methods indicated that phylogeny, systematics and ecology are strongly represented in recent cycad literature, while there is a need for more research in horticulture and pathology, reviews and clarification of correspondence between current and discontinued species designations.

Keywords: Bowenia, Ceratozamia, cycad, Cycas, Dioon, Encephalartos, Google Scholar, Lepidozamia, Macrozamia, Microcycas, Stangeria, Zamia.

DOI: http://dx.doi.org/10.11609/jott.2369.8.3.8575-8582

Editor: Ravi Prasad Rao, Sri Krishnadevaraya University, Anantapuramu, India.

Date of publication: 26 March 2016 (online \& print)

Manuscript details: Ms \# 2369 | Received 18 October 2015 | Finally accepted 12 March 2016

Citation: Cascasan, A.N. \& T. E. Marler (2016). Publishing trends for the Cycadales, the most threatened plant group. Journal of Threatened Taxa 8(3): 8575-8582; http://dx.doi.org/10.11609/jott.2369.8.3.8575-8582

Copyright: (c) Cascasan \& Marler 2016. Creative Commons Attribution 4.0 International License. JoTT allows unrestricted use of this article in any medium, reproduction and distribution by providing adequate credit to the authors and the source of publication.

Funding: None.

Conflict of Interest: The authors declare no competing interests.

Author Details: APRIL CASCASAN is a graduate student with a specialization in ecology, evolution, conservation biology at the Department of Botany, University of Hawaii at Manoa. She is studying evolutionary relationships of endemic Hawaiian Myoporum. THOMAS MARLER is a professor with the University of Guam. He is a terrestrial ecologist engaged in research and conservation of plants of importance in western Pacific island nations.

Author Contribution: Development of concepts for experimental methods was shared by both authors, ANC was responsible for all data collection and data entry. Both authors shared the authoring and editing role.

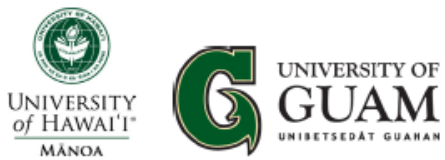




\section{INTRODUCTION}

Cycads are the most threatened group of plants, with more than $63 \%$ of described taxa listed as threatened (Brummitt et al. 2015; Fragniere et al. 2015). Cycads can be traced to the late Carboniferous period and offer unique research opportunities for contemporary scientists (Brenner et al. 2003; Donaldson 2003). Nevertheless, the quantity and breadth of accessible published research on this ancient and important group of plants is limited (Dehgan 1983; Sabato \& de Luca 1985; Moretti et al. 1993; Norstog \& Nicholls 1997; Vovides et al. 2003, 2004).

International conferences on cycad biology were initiated in 1987 and have been held every three or four years since, with published proceedings. Few attempts have been made to summarize these proceedings and/ or the rest of the primary literature in this field (Terry et al. 2012; Vovides et al. 2003, 2004, 2007), and to our knowledge there have been no attempts to capture recent trends in cycad biology over the past 30 years. We set out to do this using Google Scholar to access the primary literature coinciding with years in which international conferences of cycad biology were held up to 2008 (the most recently published conference proceedings). We also discuss limitations of the Google Scholar search engine and how authors may improve future access to their publications, and identify which fields of study may deserve a greater focus in the future.

\section{MATERIALS AND METHODS}

\section{Collection of data}

Publications were collected utilizing the search engine Google Scholar (scholar.google.com). The Google Scholar advanced search settings were set to show results by relevance and to omit citations and patents and to show the results in English only. Publications were retrieved by a Mozilla Firefox plug-in, Zotero (www.zotero.org). Publications were exported into a tabulated format with EndNoteX7, then quantified by Microsoft Office 365 Excel. Search terms were based on the common group name, 11 generic names and all genera with and without the search operators "and" or "or." The search terms were used and accessed between the dates of 23 June 2014 and 22 July 2014. The search produced 9,724 hits, and relevant articles were reviewed before inclusion. Articles were assigned to one of the following categories: biochemistry, conservation, cultivation, propagation, ecology, entomology, ethnobotany, neurobiology, toxicology, phylogeny, systematics, physiology, plant pathology, pollination biology and reproductive biology.

\section{Publication comparisons and range of years}

Proceedings from the international conferences of cycad biology were used to compare with publications from Google Scholar that corresponded to the same years for each of the eight proceedings. The comparisons were based on years 1984 through 2008, and grouped by the three years before each of the proceedings dates. In addition, publications retrieved by Google Scholar between the years 1802 through 2014 were used to observe long-range trends of publications that have been uploaded to the internet. Publications were totaled in intervals of 10 years beginning with the year 1800 . The last interval, 2011 through 2014 was adjusted to reflect the amount of publications of three years, rather than the other intervals, which were divided by 10 years.

\section{RESULTS}

\section{Trends from 1987 to 2008}

The number of publications accessed by Google Scholar exceeded that collected from the conference proceedings for every year except the 1990 conference (Fig. 1). The trends in number of publications from the conference proceedings were erratic with no clear pattern among the years. In contrast, the publications accessed by Google Scholar exhibited a linear increase from 1987 to 2002, and roughly doubled during that time period. The number of Google Scholar publications increased drastically from 2002 to 2008 . The greatest number of publications from the proceedings was

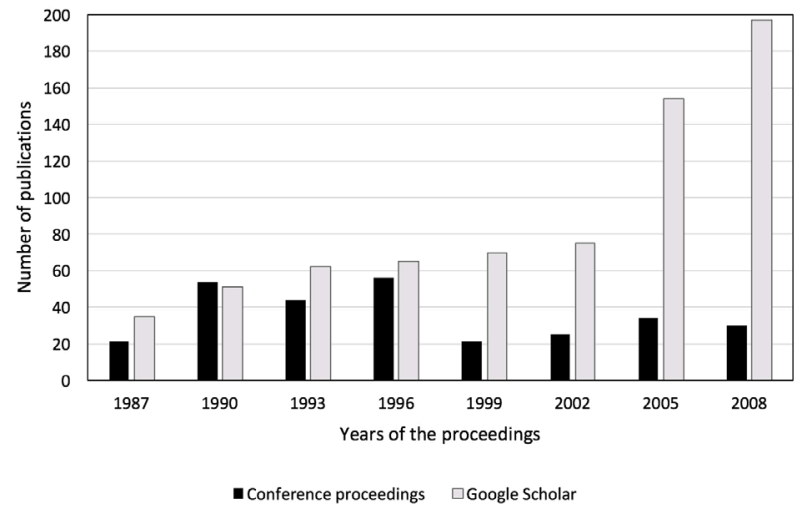

Figure 1. Total number of publications from each international cycad conference proceeding and from a Google Scholar search using the three years prior to each proceedings year as simultaneous publications for each year. 


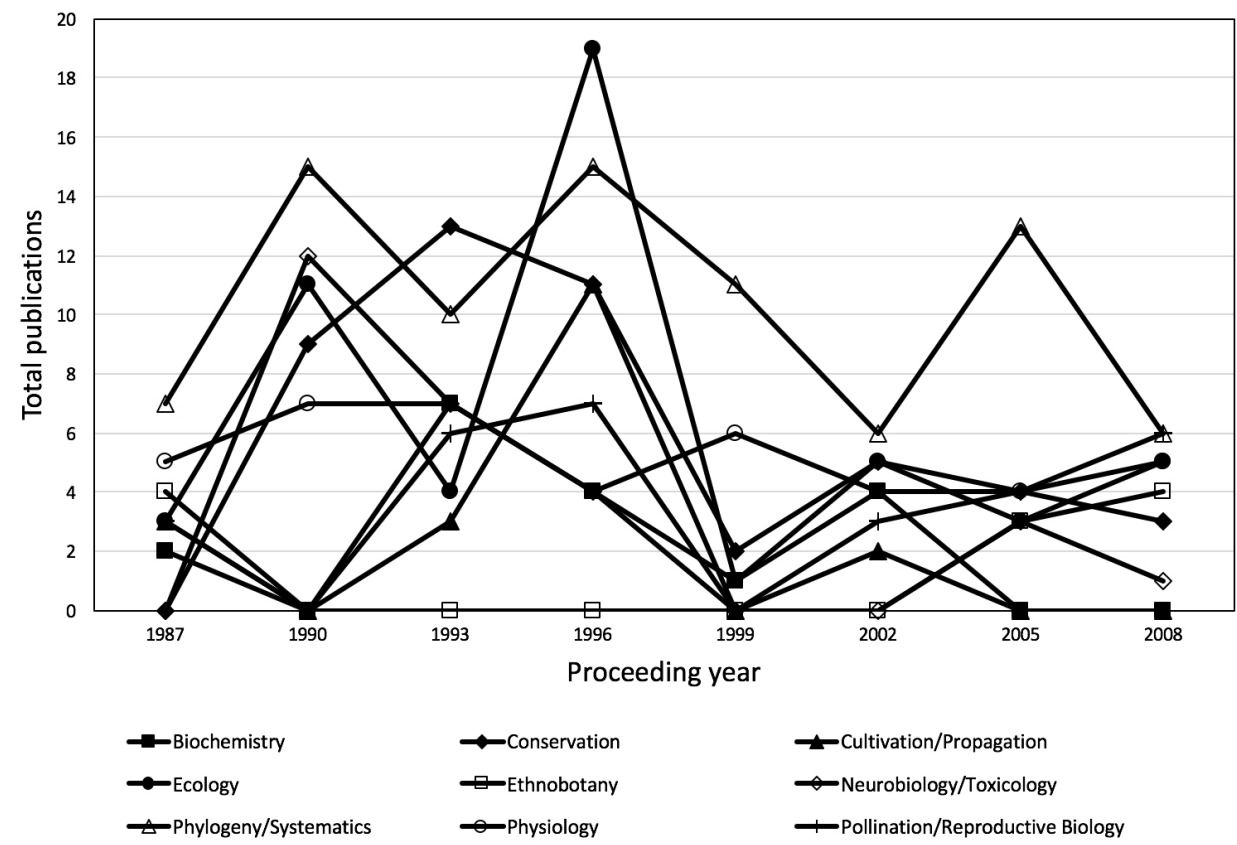

Figure 2. Total number of publications within nine subject matter categories for eight international conferences on cycad biology. in the fourth conference from 1996. The number of publications from the conferences declined in the 1999 conference and remained below what was published in the 1990s for all conferences through 2008.

\section{Fields of study in conference proceedings}

The most erratic pattern of publications in conference proceedings occurred for ecology publications, with a range of 1-19 publications (Fig. 2). Neurobiology/ toxicology papers also exhibited an erratic pattern, although not with the same amplitude as ecology. The field of study exhibiting the most stable pattern throughout the years was phylogeny/systematics, which represented a high proportion of the total number of publications in every conference proceedings. Conservation papers were well represented in 1990, 1993 , and 1996, but not in the other years. Papers on cultivation and propagation were well represented in the 1996 proceedings, but have been lacking from the remainder of proceedings. The remainder of fields of study never represented a high proportion of the total publications. The categories entomology and plant pathology were not represented in any of the conference proceedings. We included all pollinator publications in the separate pollination category.

\section{Fields of study from Google Scholar}

Google Scholar accessed more articles within the phylogeny/systematics disciplines than any other discipline throughout the years 1987-2008 (Fig. 3). The number of publications for these disciplines increased with each successive year, and an abrupt increase in the number of publications occurred between 2002 and 2005. The other disciplines were represented by less than 10 publications annually for each successive threeyear increments from 1987 to 2002. Conservation, ecology, and physiology publications noticeably increased in between 2002 and 2008.

\section{Long range trends}

The use of Google Scholar to access publications from 1800 through 2014 revealed a very limited ability to find publications until the last five decades (Fig. 4). In parallel with Fig. 3, the phylogeny/systematics and ecology disciplines exhibited the greatest volume of change in recent years, indicating the upswing in publications within these categories pre-dated the conference proceedings.

The oldest biochemistry article that was accessed was published in 1921 (Clevenger 1921). The oldest publication that was classified as a conservation article was accessed from 1978 (Frederiksen 1978). We categorized a 1958 economic botany paper (Thieret 1958) as a cultivation/propagation publication. An article by Chamberlain (1926) was considered the oldest publication on ecology. Entomology was first represented by a 1981 article by Pant et al. (1981). The oldest article from the discipline ethnobotany was 


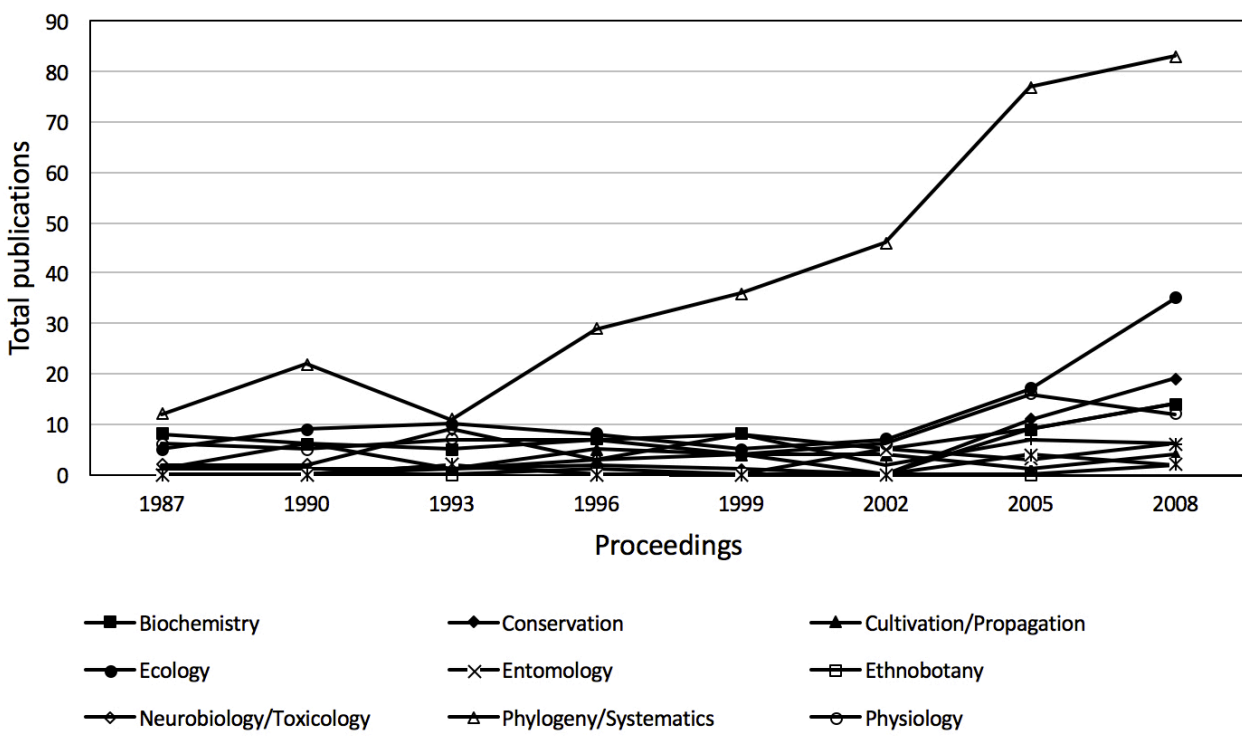

Figure 3. Total number of publications within 11 subject matter categories collected using Google Scholar. Each year represents all publications from the previous three years.

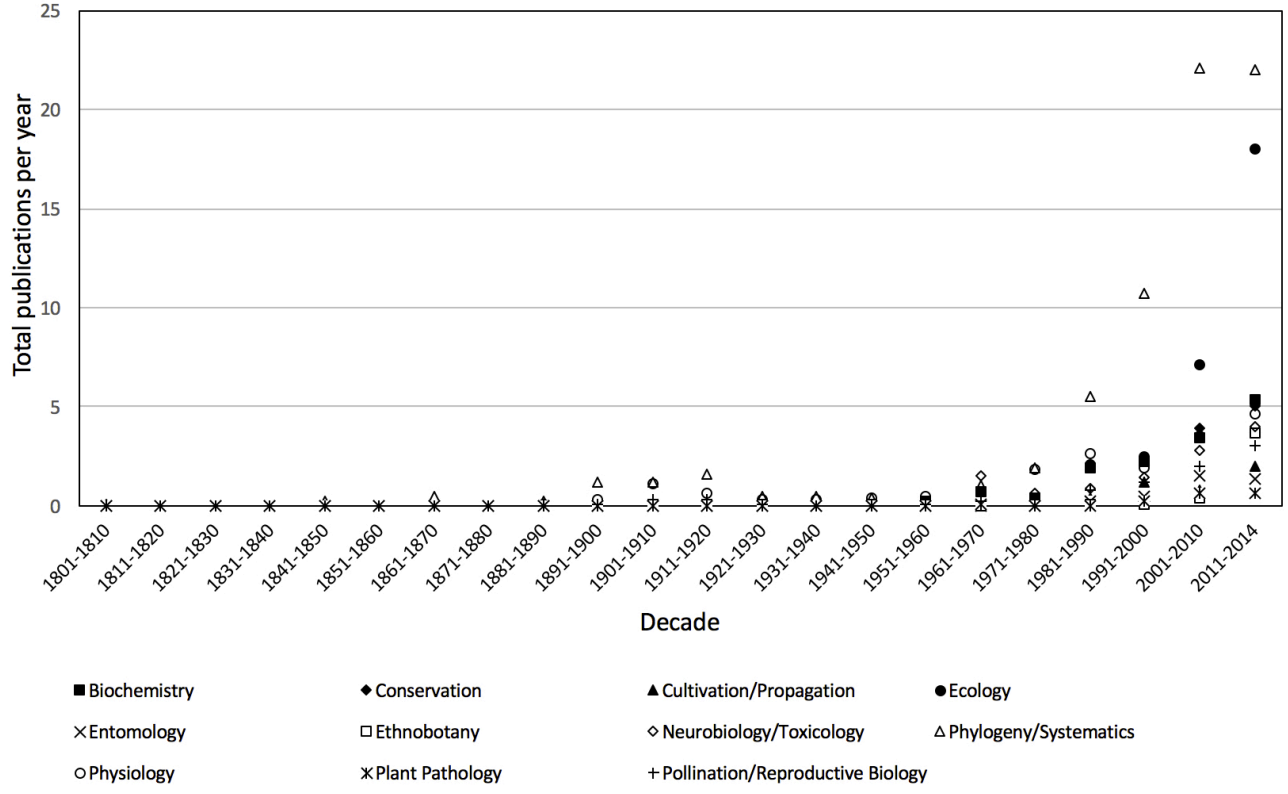

Figure 4. Total number of publications within 11 subject matter categories collected between the years 1802 and 2014 and sorted by decade. accessed from 1951 (Smith 1951). Neurobiology and toxicology disciplines were first represented in 1956 when Nishida et al. (1956) described cycasin. The category phylogeny and systematics is the only category that dates back to the early 1800s (Smith 1802). This category exhibited an increase in publications between 1891 and 1920, then a second abrupt increase beginning 1961. We categorized an 1887 article (Gregg 1887) as the oldest retrieved physiology article, and a 1970 article (Forgacs 1970) as the oldest pathology article. Lastly, the oldest article we categorized as pollination biology/ reproductive biology publication was accessed from 1898 by way of an 1899 book review (Ikeno 1898).

We quantified the number of publications for each binomial that was easily identified from search results, and nine species emerged as having more than 10 publications from the 1802 to 2014 search (Table 1). Cycas revoluta was the subject of more publications than any other cycad species. More than $50 \%$ of the $C$. revoluta papers were published since 2001 . Three other Cycas species were also represented in this short list. Only six species were clearly identified as the subject of 
Table 1. The top 10 cycad species with the most publications from Google Scholar search methods.

\begin{tabular}{|l|c|}
\hline Genus species & Total publications \\
\hline Cycas revoluta & 90 \\
\hline Cycas circinalis & 37 \\
\hline Cycas micronesica & 32 \\
\hline Dioon edule & 21 \\
\hline Macrozamia communis & 20 \\
\hline Zamia pumila & 20 \\
\hline Cycas panzhihuaensis & 17 \\
\hline Zamia floridana & 14 \\
\hline Macrozamia riedlei & 12 \\
\hline
\end{tabular}

20 or more publications.

\section{DISCUSSION}

Scientific information management is becoming critical due to the burgeoning online database of publications. All of the publications that convey information about cycads should be valued for contributing to building the foundation of knowledge needed to understand and conserve this plant group. The extensive work on cycad biology carried out since the international cycad conferences were begun in 1987 has rendered wide-ranging information that needs to be fully organized and condensed to enable a wealth of desirable information.

Both of our search methods indicated that phylogeny, systematics and ecology are among the disciplines that are most heavily represented in recent cycad literature. Google Scholar results indicated conservation, biochemistry and physiology publications were also increasing in quantity in recent years. In contrast, publications within these disciplines did not increase in recent conference proceedings. The study of cycad horticulture and physiology has been inadequate even though the International Union for Conservation of Nature recommends improved efforts to propagate and cultivate cycads to advance conservation efforts (Donaldson 2003). Considering the fact that more than $63 \%$ of described cycad taxa are listed as threatened (Brummitt et al. 2015; Fragniere et al. 2015), this means that most of the described species have not been directly studied to refine their horticultural needs. This lack of applied research hinders conservation efforts.

The publisher of each cycad conference proceedings has control over how effectively Google Scholar is able to find the articles. For example, the 1990 conference was the only conference that revealed more publications in the proceedings than in corresponding Google Scholar publications (Fig. 1). These proceedings were published as a stand-alone book by the Palm \& Cycad Societies of Australia. Because the proceedings from these conferences generally take 2 or 3 years to publish, our methods would have found those articles in the Google Scholar search for the 1993 data. The trends in Fig. 1 indicated that Google Scholar was unable to find most of the articles from the conference proceedings in the earliest conferences, but was able to find the articles from the conference proceedings in more recent conferences.

Attempts to advance cycad biology research are diminished when articles containing data on cycads are published without sufficient titles or keywords (e.g., Beaton 1991; Wright \& Westoby 2003; McAdam $\&$ Brodribb 2015). Numerous articles from the medical literature have been published on neurodegeneration and included administration of the cycad tissue to test subjects. This vast literature is one example of what was not captured by our search methods because the authors did not include key words that enabled a hit. Hao et al. (2014) studied this phenomenon for agroforestry literature and suggested that the word "agroforestry" be prominently located in the title to increase search engine access. As a minimum, we suggest a similar approach by the inclusion of "cycad" and the genus of each cycad taxon in the publication title or key word list.

Google Scholar is quick in retrieving results, but not very selective. Of the 9,724 publications retrieved using Google Scholar, 63\% were omitted for this study. Most of these were omitted due to duplication (Haddaway et al. 2015). Google Scholar is dependent on the precise metadata (title, author, journal etc.) entered with each publication. If these metadata were incorrectly keyed in (misspelling or differing in the number of spaces) or were keyed in differently (abbreviations used for title or author), Google Scholar registers the publications as separate hits despite the fact they are the same publication. A total amount of 3,636 publications remained after this first culling, but only $35 \%$ of these were unambiguously cycad publications. Fortunately, the first few pages of hits were the most relevant (Haddaway et al. 2015). Google Scholar can only retrieve up to 1,000 results at any time. After the first 100 results, there is a timed block, preventing a researcher from 
searching Google Scholar; a feature that does not apply to the regular Google search engine. For this study, a work around was used to bypass the block.

Our exercise in retrieving publications beginning 1801 was an attempt to define the origin of digitized publications on cycad biology as a whole. A majority of the publications that were retrieved from the years 1801 through 1950 were categorized under phylogeny and systematics. The existence of these articles, albeit few, serves as the foundation for the field of cycad biology. The "silence" during those 150 years will likely improve with time, as more historical publications from the primary literature are digitized and uploaded to the internet. Scott (2004) searched for bibliographic information of geoscience literature that predated the 1900 s and found that much of it had not been digitized. Bibliographic databases do not contain full text journals but are beneficial due to the wide range of years a researcher can uncover on a specific topic (Jesson et al. 2011). However, the range of years of publications that have been indexed by Google Scholar is not known (Jacso 2005). The earliest article retrieved for this study was published in 1802, but earlier publications may become available in future searches as more historical publications are digitized and uploaded.

Publications on Cycas circinalis and Zamia pumila represent problematic assessments because these binomials have been used for many taxa that are no longer considered $C$. circinalis or Z. pumila. Identification and classification of taxa have been revised many times, and some records may be inaccurate. Research is still ongoing for resolving many phylogenies. In order to determine how easily these retrospective changes in epithet could be corrected, we tried to determine the origin of the plants used for each publication as discerned by information extracted from the abstract or methods. Of the Cycas circinalis publications, $11 \%$ unambiguously originated from Guam. A correction in the publication list in Table 1 would indicate there were 36 Cycas micronesica (the Cycas from Guam) and 33 Cycas circinalis publications, advancing Cycas micronesica to second on the list. Similarly, $70 \%$ of the Zamia pumila publications contained information on where the Zamia occurred. Some of these publications may actually be on Zamia floridana.

\section{SUGGESTIONS}

a. Our results indicate that the global community has not adequately responded to the IUCN's suggestions concerning improved propagation and cultivation of rare cycad taxa (Donaldson 2003). More applied horticulture research on each of the threatened species is needed to adequately respond to this need.

b. The lack of publications on cycad pathology is an indication that diseases are not among the greatest limitations for growing cycads or representative of the most important threats to cycad conservation. Despite these reasons for the lack of historical research on pathology, we suggest greater interest in focused research on cycad diseases to fill this void.

c. Few attempts have been made to review portions of the cycad literature (Vovides et al. 2003, 2004, 2007; Terry et al. 2012). The immense literature on phylogeny and systematics is in effect reviewed with each update of "The World List of Cycads" that appears in each set of conference proceedings, but a review on how tools and methods have evolved over the years may be warranted. The recent increase in publications on cycad ecology and how those recent publications contribute to the historical foundation of knowledge on this subject indicates a review on this subject is overdue. Some portions of the cycad literature may have accumulated to the point that meta-analyses are possible.

d. One endeavor that would clarify the cycad literature would be a retrospective assessment of all publications from the species complexes, as the names within these complexes have been heavily modified over the years. The ongoing updates of epithets that coincide with accepted cycad taxa can be found in the sequential publications of The World List of Cycads in each of the conference proceedings. However, using the contemporary list of binomials to correct all past publications that used a previously accepted binomial has not been done to date. A knowledgeable cycad biologist could correct each of the historical publications to be properly attached to the contemporary accepted name for each publication. The results would clarify the cycad literature for all users, especially for the literature on Cycas circinalis and Zamia pumila.

e. The first of two increases in the number of phylogeny and systematic publications occurred between 1891 and 1920 (Fig. 4). A detailed look at this historical phenomenon and how it compares with the recent increase of publications in the same categories would be of interest.

f. Our suggestion to include "cycad" and the genus of each cycad taxon in a publication title or keyword list cannot retrospectively correct historical oversights in the original publications. However, the recent emergence of social networking sites for scientists, 
such as ResearchGate, offer an updated opportunity for authors to improve their list of keywords associated with an uploaded publication. The custom list of keywords allowed by the researcher could include our suggested key words.

g. The application of web-based data to improve the advancement of cycad biology need not be restricted to standard search engines that search the primary literature. Studying search behavior directly, quantifying how online journalism information links to research, web-crawling approaches to uncovering trends, and embracing social networking approaches (Proulx et al. 2013; Kim et al. 2014; Parsons et al. 2014; Do et al. 2015; Papworth et al. 2015) all promise to have a role in keeping up with cycad biology developments, if appropriate cycad researchers elect to employ these tools. This may serve as an example of the principles that underlie the Red Queen hypothesis (van Valen 1973), which proposes that constant adaptation and proliferation is required to simply to survive while responding to ever-evolving and ever-changing environments. The failure to apply these evolving web-based tools to the cycad literature may hinder progress in understanding this segment of the literature at the same pace as progress in the remainder of the biology literature.

In summary, the general trends of cycad research in biochemistry, conservation, cultivation, propagation, ecology, entomology, neurobiology, toxicology, phylogeny, systematics, physiology, and plant pathology are increasing in recent years. Phylogeny, systematics, and ecology have been highly represented in the recent cycad literature. Our results indicate that Cycas revoluta is the subject of more published cycad research than any other cycad species. Moreover, the horticulture and pathology related fields have not been adequately represented in publications. Continued assessments such as this may reveal which components of cycad research have accumulated a sufficient body of literature to enable meta-analyses and detailed reviews. The Google Search engine is powerful but does have limitations and cannot function autonomously. Google Scholar is clearly a valuable tool for readers and authors to utilize in searching for cycad literature.

\section{REFERENCES}

Beaton, J.M. (1991). Excavations at Rainbow Cave and Wanderer's Cave: two rockshelters in the Carnarvon Range, Queensland. Queensland Archaeological Research 8: 3-32.

Brenner, E.D., D.W. Stevenson \& R.W. Twigg (2003). Cycads: evolutionary innovations and the role of plant-derived neurotoxins. Trends in Plant Science 8: 446-452; http://dx.doi.org/10.1016/
S1360-1385(03)00190-0

Brummitt, N.A., S.P. Bachman, J. Griffiths-Lee, M. Lutz, J.F. Moat, A. Farjon, J.S. Donaldson, C. Hilton-Taylor, T.R. Meagher, S. Albuquerque, E. Aletrari, A.K. Andrews, G. Atchison, E. Baloch, B. Barlozzini, A. Brunazzi, J. Carretero, M. Celesti, H. Chadburn, E. Cianfoni, C. Cockel, V. Coldwell, B. Concetti, S. Contu, V. Crook, P. Dyson, L. Gardiner, N. Ghanim, H. Greene, A. Groom, R. Harker, D. Hopkins, S. Khela, P. Lakeman-Fraser, H. Lindon, H. Lockwood, C. Loftus, D. Lombrici, L. Lopez-Poveda, L. Lyon, K. Malcolm-Tompkins, L. Moreno, L. Murray, K. Nazar, E. Power, M.Q. Tuijelaars, R. Salter, R. Segrott, H. Thacker, L.J. Thomas, S. Tingvoll, G. Watkinson, K. Wojtaszekova \& E.M.N. Lughadha (2015). Green plants in the red: A baseline global assessment for the IUCN sampled Red List Index for plants. PloS one 10(8): e0135152; http://dx.doi.org/10.1371/ journal.pone.0135152

Chamberlain, C.J. (1926). Hybrids in cycads. Botanical Gazette 81: 401-418.

Clevenger, J.F. (1921). A report on the Zamia starch situation. Journal of the American Pharmaceutical Association 10(11): 837-840. [First published online 2006, but from 1921]

Dehgan, B. (1983). Propagation and growth of cycads - a conservation strategy. Proceedings of the Florida State Horticultural Society 96: 137-139

Do, Y., J.Y. Kim, M. Lineman, D.K. Kim \& G.J. Joo (2015). Using Internet search behavior to assess public awareness of protected wetlands. Conservation Biology 29(1): 271-279; http://dx.doi.org/ 10.1111/ cobi.12419

Donaldson, J.S. (ed.). (2003). Cycads. Status Survey and Conservation Action Plan. IUCN/SSC Cycad Specialist Group. IUCN, Gland, Switzerland and Cambridge, UK, ix+86pp.

Forgacs, J. (1970). Mycologie and mycotoxic examination of cycads. pp. 75-99. In: Purchase, I.F.H. (ed.). Mycotoxins in Human Health. Macmillan, London.

Fragniere, Y., S. Bétrisey, L. Cardinaux, M. Stoffel \& G. Kozlowski (2015). Fighting their last stand? A global analysis of the distribution and conservation status of gymnosperms. Journal of Biogeography 42(5): 809-820.

Frederiksen, N.O. (1978). Preservation of cycad and Ginkgo pollen. Review of Palaeobotany and Palynology 25(2): 163-179.

Gregg, W.H. (1887). Anomalous thickening in the roots of Cycas seemanni, Al. Braun with Plate VI. Annals of Botany 1(1): 63-70.

Haddaway, N.R., A.M. Collins, D. Coughlin \& S. Kirk (2015). The role of Google Scholar in evidence reviews and its applicability to grey literature searching. PloS one 10(9): e0138237.

Hao, H., C. Grimaldi \& C. Walter (2014). Using "agroforestry" in the title: serving potential readers better by increasing the chances of being found by search engines. Agroforestry Systems 88(2): 383384; http://dx.doi.org/10.1007/s10457-013-9667-0

Ikeno, S. (1898). Untersuchungen ueber die Entwicklung der Geschlechtsorgane und den Vorgang der Befruchtung bei Cycas revoluta. The Journal of the College of Science, Imperial University of Tokyo, Japan 12(3): 151-214 (as reviewed by American Naturalist 33: 751-753).

Jacso, P. (2005). As we may search - comparison of major features of the Web of Science, Scopus, and Google Scholar citation-based and citation-enhanced databases. Current Science 89(9): 1537-1547.

Jesson, J., L. Matheson \& F.M. Lacey (2011). Doing your Literature Review: Traditional and Systematic Techniques. Sage, London

Kim, J.Y., Y. Do, R.Y. Im, G.Y. Kim \& G.J. Joo (2014). Use of large webbased data to identify public interest in trends related to endangered species. Biodiversity and Conservation 23(12): 2961-2984; http:// dx.doi.org/10.1007/s10531-014-0757-8

McAdam, S.A.M. \& T.J. Brodribb (2015). Hormonal dynamics contributes to divergence in seasonal stomatal behaviour in a monsoonal plant community. Plant, Cell and Environment 38(3): 423-432; http://dx.doi.org/10.1111/pce.12398

Moretti, A., S. Sabato \& G.S. Gigliano (1981). Monosaccharide composition of the mucilages in Encephalartos Lehm. (Zamiaceae). Plant Biosystem 115(6): 291-297; http://dx.doi. 
org/10.1080/11263508109427986

Nishida, K., A. Kobayashi \& T. Nagahama (1956). 12. Studies on cycasin, a new toxic glycoside, of Cycas revoluta Thunb. Bulletin of the Agricultural Chemical Society of Japan 19(1): 77-84; http:// dx.doi.org/10.1080/03758397.1955.10857267

Norstog, K.J. \& T.J. Nicholls (1997). The Biology of The Cycads. Cornell University Press, Ithica, New York, xi+363pp.

Pant, D.D., D.D. Nautiyal \& S.K. Chaturvedi (1981). Microscopic examination of faecal pellets of insect larvae feeding on leaves of some cycads. Proceedings: Plant Sciences 90(6): 509-514; http:// dx.doi.org/10.1007/BF03052950

Papworth, S.K., T.P.L. Nghiem, D. Chimalakonda, M.R.C. Posa, L.S. Wijedasa, D. Bickford \& L.R. Carrasco (2015). Quantifying the role of online news in linking conservation research to Facebook and Twitter. Conservation Biology 29: 825-833; http://dx.doi. org/10.1111/cobi.12455

Parsons, E.C.M., D.S. Shiffman, E.S. Darling, N. Spillman \& A.J. Wright (2014). How Twitter literacy can benefit conservation scientists. Conservation Biology 28(2): 299-301; http://dx.doi.org/10.1111/ cobi.12226

Proulx, R., P. Massicotte \& M. Pépino (2014). Googling Trends in Conservation Biology. Conservation Biology 28: 44-51; http:// dx.doi.org/10.1111/cobi.12131

Sabato, S. \& S. de Luca (1985). Evolutionary trends in Dion (Zamiaceae). American Journal of Botany 72: 1353-1363.

Scott, M.W. (2003). Status of bibliographic control of pre-1900 geoscience literature. Geoscience Information Society Proceedings 34: 105-108.
Smith, H.G. (1951). The ethnological and archeological significance of Zamia. American Anthropologist 53(2): 238-244; http://dx.doi. org/10.1525/aa.1951.53.2.02a00060

Smith, J.E. (1802). XXIII. Description of the fruit of Cycas revoluta. Transactions of the Linnean Society of London 6(1): 312-315; http:// dx.doi.org/10.1111/j.1096-3642.1802.tb00488.x

Terry, I., W. Tang, A.S.T. Blake, J.S. Donaldson, R. Singh, A.P. Vovides \& A.C. Jaramillo (2012). An overview of cycad pollination studies. Memoirs of the New York Botanical Garden 106: 352-394.

Thieret, J. (1958). Economic botany of the cycads. Economic Botany 12(1): 3-41; http://dx.doi.org/10.1007/BF02863122

van Valen, L. (1973). A new evolutionary law. Evolutionary Theory 1: 1-30.

Vovides, A.P., M.A. Pérez-Farrera, J. Gonzáles-Astorga, D. González, T. Gregory, J. Chemnick, C. Iglesias, P. Octavio-Aguilar, S. Avendaño, C. Bárcenas \& S. Salas-Morales (2003). An outline of our current knowledge on Mexican cycads (Zamiaceae, Cycadales). Current Topics in Plant Biology 4: 159-174.

Vovides, A.P., D. González, M.A. Pérez-Farrera, S. Avendaño \& C. Bárcenas (2004). A review of research on the cycad genus Ceratozamia Brongn. (Zamiaceae) in Mexico. Taxon 53: 291-297; http://dx.doi.org/10.2307/4135609

Vovides, A.P., J. González-Astorga, M.A. Pérez-Farrera, D. González, C. Bárcenas \& C. Iglesias (2007). The cycads of Mexico: 25 years of research and conservation. Memoirs of the New York Botanical Garden 97: 611-641.

Wright, I.J. \& M. Westoby (2003). Nutrient concentration, resorption and lifespan: leaf traits of Australian sclerophyll species. Functional Ecology 17: 10-19; http://dx.doi.org/10.1046/j.13652435.2003.00694.x 